\title{
Disease activity in ankylosing spondylitis: the global therapeutic target
}

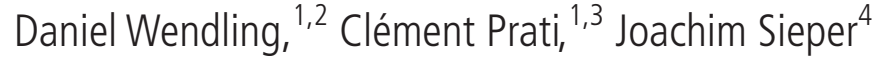

Spondyloarthritis (SpA) is a multifaceted disease with frequent predominant axial involvement. ${ }^{1}$ Typical sacroiliac radiographic changes allow to classify the patients as ankylosing spondylitis (AS). Imaging is able to classify patients as AS or non-radiographic axial spondyloarthritis (axSpA) and illustrate and recognise the several steps from inflammation to structural damage, particularly in sacroiliac joints and spine. For decades, these radiographic findings have been the cornerstone for the classification and diagnosis of the disease. ${ }^{1}$ Contrary to other chronic rheumatic diseases such as rheumatoid arthritis, radiographic progression over time is only of limited interest as an outcome measure of the disease in the follow-up of patients with AS in current practice. In fact, radiographic progression is slow and does not even occur in all patients, has a low sensitivity to change over time and is associated with unidirectional evolution without regression. The tool used in current research to quantify the structural damage of the spine in AS is the modified Stoke Ankylosing Spondylitis Spinal Score (mSASSS), which gives higher scores for ossification and bridging of the vertebrae (which may represent a repair mechanism) than for erosive ('inflammatory') changes. Advanced structural changes are associated with functional and spinal mobility impairment. ${ }^{2}$

During the last decade, the use of anti-TNF agents has represented a major breakthrough in the treatment of patients with AS and with $\mathrm{SpA}$ in general as well. $^{3}$ But, whereas they demonstrated high effectiveness in controlling signs and symptoms of the disease (including

1Department of Rheumatology, CHRU de Besançon, University Teaching Hospital, Besancon, France 'EA4266 EPILAB, Université Bourgogne Franche-Comté, Besançon, France

${ }^{3} \mathrm{FHU}$ Increase, Université Bourgogne Franche-Comté, Besançon, France

${ }^{4}$ Department of Rheumatology, Charité- Campus Benjamin Franklin, Berlin, Germany

Correspondence to Dr Daniel Wendling, Department of Rheumatology, CHRU de Besançon, University Teaching Hospital, Besancon 25030, France; dwendling@chu-besancon.fr extra-articular manifestations, quality of life, productivity), the attempts to illustrate/demonstrate a potential reduction in radiographic progression under TNF inhibition (using mSASSS over a 2 -year period and comparison to a historical cohort of patients with AS not treated with TNF blockers) have failed. ${ }^{4}$ Several potential risk factors for radiographic progression in AS have been suggested, such as smoking, elevated $\mathrm{C}$ reactive protein (CRP) levels, low non steroidal anti inflammatory drug (NSAID) intake, baseline presence of syndesmophytes, high scores for disease activity and various biomarkers (vascular endothelial growth factor (VEGF), calprotectin, adipokines). ${ }^{3}$

In Annals of the Rheumatic Diseases, Molnar et $a l^{5}$ evaluated radiographic progression in AS, using the database of the Swiss cohort patients with AS and spine radiographic follow-up every 2 years, although this analysis was based in about $2 / 3$ of the patients on only one radiographic interval of 2 years. This study included 432 with long-standing, real-life classical AS patients with AS and syndesmophytes, and 616 intervals with two consecutive X-rays and used a statistical model adjusted for the potential factors associated with radiographic progression of the spine and a model adjusted for ASDAS (Ankylosing Spondylitis Disease Activity Score) value before start of anti-TNF agents. In multivariable analysis, prior anti-TNF treatment was associated with a reduction by $50 \%$ of the odds for radiographic progression (defined as an increase of at least 2 units of the mSASSS or appearance of at least one new syndesmophyte in 2 years) during the next 2 -year interval. Their results suggest that a longer duration of anti-TNF exposition is associated with a stronger protective effect. Moreover, using the above-mentioned model, they found that this effect seems to be mediated through the control of disease activity; patients with an ASDAS less or equal 1.3 (inactive disease) under anti-TNF treatment did not show radiographic progression at all.
Several aspects from this study should be discussed.

First, this study shows an effect of TNF-blocker therapy on structural damage in the spine with a fair level of evidence. Previous reports suggested a potential relationship, using retrospective analysis over a long period, ${ }^{6-9}$ but in the absence of a controlled study (that would probably never been performed), confirmation applying sophisticated statistical models is of value.

This kind of study with results drawn from retrospective data analysis demonstrates the usefulness of well-built cohorts; several are available, and some focused on early stages of the disease, ${ }^{1011}$ with promising forthcoming results. Moreover, this study gives the opportunity for validation of a definition of radiographic progression (at least 2 mSASSS units over 2 years) and validation of an operational ASDAS cut-off (less or equal 1.3) for remission or inactive disease in real life. ${ }^{12} 13$ These are useful tools for further studies and in clinical settings as well in case of the ASDAS.

Second, the results of this study underline the importance of controlling disease activity, thus confirming previous studies suggesting such a relationship between disease activity, measured by $\mathrm{CRP}^{14}$ or ASDAS, ${ }^{15} 16$ and radiographic progression on a cross-sectional level. Regarding the association disease activity-radiographic progression, the observation of non-progression after reaching remission may represent an argument of a link of causality between these two, also suggested by the association between dose tapering of TNF inhibitors and more rapid progression in AS patients with syndesmophytes. ${ }^{17}$ However, suppression of clinical disease activity by long-term TNF-blockers might be more relevant than radiographic progression for clinical outcome parameters such as function and spinal mobility. ${ }^{18}$

The results of the study by Molnar et $a l^{5}$ raise the question: can the equation/ association 'induced remission leading to absence of radiographic evolution' be extrapolated to other treatments with different mode of action, such as NSAIDs or other biologics and to other subsets of SpA? This needs to be demonstrated. ${ }^{19} 20$

Finally, these data give sense to a treat-totarget (T2T) strategy ${ }^{21}$ with benefit for signs and symptoms and for structural damage as well and, as a consequence of this, on function, even in more advanced diseases. Clinical remission reached by an effective anti-inflammatory treatment such as TNF-blockers may lead to non-progression of structural damage, particularly in case 
of early initiation, ${ }^{22}$ since bone formation seems secondary to local inflammation. ${ }^{23}$

In conclusion, the results of this study represent a plea for a tight control of disease activity in AS and potentially in SpA in general as well, assessed by the ASDAS. There is now more and more evidence that remission/inactive disease defined by an ASDAS $<1.3$ is a worthwhile treatment ('T2T') aim with long-term consequences. ASDAS is easy to evaluate and to use in current practice compared with radiographic scoring. This defines a clear target for the therapeutic strategies in axial SpA.

Contributors All authors contributed significantly to this Editorial.

Competing interests DW received speaking fees from Abbvie, BMS, MSD, Pfizer, RochebChugai, Amgen, SOBI, Novartis, Janssen, Hospira, Lilly, Sandoz, UCB, and advisory board for Novartis, Sandoz, Celgene. CP received speaking fees from UCB, Pfizer, Roche Chugai, Lilly, Novartis, MSD, Abbvie, BMS, and advisory board for Novartis. JS received speaking fees from Abbvie, BMS, MSD, Pfizer, UCB, Novartis, Janssen and Lilly

Provenance and peer review Commissioned; externally peer reviewed.

(c) Article author(s) (or their employer(s) unless otherwise stated in the text of the article) 2018. All rights reserved. No commercial use is permitted unless otherwise expressly granted.

\section{(D) Check for updates}

To cite Wendling D, Prati C, Sieper J. Ann Rheum Dis 2018:77:1095-1096.

\section{CLinked}

- http://dx.doi.org/10.1136/annrheumdis-2017211544

Ann Rheum Dis 2018;77:1095-1096.

doi:10.1136/annrheumdis-2017-212363

\section{REFERENCES}

1 Sieper J, Poddubnyy D. Axial spondyloarthritis. Lancet 2017:390:73-84.

2 Wanders A, Landewé R, Dougados $\mathrm{M}$, et al. Association between radiographic damage of the spine and spinal mobility for individual patients with ankylosing spondylitis: can assessment of spinal mobility be a proxy for radiographic evaluation? Ann Rheum Dis 2005;64:988-94.

3 Prati C, Claudepierre P, Goupille P, et al. TNF $\alpha$ antagonist therapy in axial spondyloarthritis: can we do better? Joint Bone Spine 2016;83:247-9.

4 van der Heijde D, Landewé R, Baraliakos X, et al. Radiographic findings following two years of infliximab therapy in patients with ankylosing spondylitis. Arthritis Rheum 2008;58:3063-70.

5 Molnar C, Scherer A, Baraliakos X, et al. Rheumatologists of the Swiss Clinical Quality Management Program. TNF blockers inhibit spinal radiographic progression in ankylosing spondylitis by reducing disease activity: results from the Swiss Clinical Quality Management cohort. Ann Rheum Dis 2018;77:63-9.

6 Haroon N, Inman RD, Learch TJ, et al. The impact of tumor necrosis factor $\alpha$ inhibitors on radiographic progression in ankylosing spondylitis. Arthritis Rheum 2013;65:2645-54

7 Baraliakos $\mathrm{X}$, Haibel $\mathrm{H}$, Listing J, et al. Continuous long-term anti-TNF therapy does not lead to an increase in the rate of new bone formation over 8 years in patients with ankylosing spondylitis. Ann Rheum Dis 2014;73:710-5.

8 Maas F, Arends S, Wink FR, et al. Ankylosing spondylitis patients at risk of poor radiographic outcome show diminishing spinal radiographic progression during long-term treatment with TNF- $\alpha$ inhibitors. PLoS One 2017; 12:e0177231.

9 Maas F, Arends S, Brouwer E, et al. Reduction in spinal radiographic progression in ankylosing spondylitis patients receiving prolonged treatment with tumor necrosis factor inhibitors. Arthritis Care Res 2017:69:1011-9.

10 van den Berg R, de Hooge M, Rudwaleit M, et al. ASAS modification of the Berlin algorithm for diagnosing axial spondyloarthritis: results from the SPondyloArthritis Caught Early (SPACE)-cohort and from the Assessment of SpondyloArthritis international Society (ASAS)-cohort. Ann Rheum Dis 2013;72:1646-53

11 Dougados M, Etcheto A, Molto A, et al. Clinical presentation of patients suffering from recent onset chronic inflammatory back pain suggestive of spondyloarthritis: the DESIR cohort. Joint Bone Spine 2015:82:345-51.

12 Wendling D, Prati C. Remission in axial spondyloarthritis: the ultimate treatment goal? Joint Bone Spine 2016;83:117-9.

13 Wendling D, Guillot X, Gossec L, et al. Remission is related to CRP and smoking in early axial spondyloarthritis. The DESIR cohort. Joint Bone Spine 2017:84:473-6.
14 Poddubnyy $\mathrm{D}$, Haibel $H$, Listing J, et al. Baseline radiographic damage, elevated acute-phase reactant levels, and cigarette smoking status predict spinal radiographic progression in early axial spondylarthritis. Arthritis Rheum 2012;64:1388-98.

15 Ramiro S, van der Heijde D, van Tubergen A, et al. Higher disease activity leads to more structural damage in the spine in ankylosing spondylitis: 12-year longitudinal data from the OASIS cohort. Ann Rheum Dis 2014:73:1455-61.

16 Poddubnyy D, Protopopov M, Haibel H, et al. High disease activity according to the Ankylosing Spondylitis Disease Activity Score is associated with accelerated radiographic spinal progression in patients with early axial spondyloarthritis: results from the GErman SPondyloarthritis Inception Cohort. Ann Rheum Dis 2016;75:2114-8.

17 Park JW, Kwon HM, Park JK, et al. Impact of dose tapering of tumor necrosis factor inhibitor on radiographic progression in ankylosing spondylitis. PLoS One 2016;11:e0168958.

18 Poddubnyy D, Fedorova A, Listing J, et al. Physical function and spinal mobility remain stable despite radiographic spinal progression in patients with ankylosing spondylitis treated with TNF- $\alpha$ Inhibitors for Up to 10 Years. J Rheumatol 2016;43:2142-8

19 Proft F, Muche B, Listing J, et al. Study protocol: COmparison of the effect of treatment with Nonsteroidal anti-inflammatory drugs added to antitumour necrosis factor a therapy versus anti-tumour necrosis factor a therapy alone on progression of StrUctural damage in the spine over two years in patients with ankyLosing spondylitis (CONSUL) - an open-label randomized controlled multicenter trial. BMJ Open 2017;7:e014591.

20 Sieper J, Listing J, Poddubnyy D, et al. Effect of continuous versus on-demand treatment of ankylosing spondylitis with diclofenac over 2 years on radiographic progression of the spine: results from a randomised multicentre trial (ENRADAS). Ann Rheum Dis 2016;75:1438-43.

21 Smolen JS, Schöls M, Braun J, et al. Treating axial spondyloarthritis and peripheral spondyloarthritis, especially psoriatic arthritis, to target: 2017 update of recommendations by an international task force. Ann Rheum Dis 2018;77:3-17.

22 Zhang JR, Liu XJ, Xu WD, et al. Effects of tumor necrosis factor- $\alpha$ inhibitors on new bone formation in ankylosing spondylitis. Joint Bone Spine 2016:83:257-64.

23 Tseng HW, Pitt ME, Glant TT, et al. Inflammation-driven bone formation in a mouse model of ankylosing spondylitis: sequential not parallel processes. Arthritis Res Ther 2016;18:35. 